\title{
La ciudad como un libro abierto: el flâneur como lector y escritor del espacio híbrido a través de la práctica artística
}

\author{
The city as an open book: the flâneur as reader and \\ writer of hybrid space through artistic practice
}

Elia Torrecilla

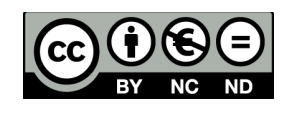

Esta obra está bajo una licencia Creative Commons Reconocimiento-No comercial-Sin Obra Derivada 


\title{
La ciudad como un libro abierto: el flâneur como lector y escritor del espacio híbrido a través de la práctica artística
}

\section{The city as an open book: the flâneur as reader and writer of hybrid space through artistic practice}

\author{
Elia Torrecilla ${ }^{2}$ \\ Universidad Miguel Hernández de Elche \\ España
}

Recibido: 23 de enero de 2020 Aprobado: 17 de marzo de 2020

\begin{abstract}
Resumen
La metáfora de la ciudad como libro abierto despierta la curiosidad de un paseante-lector, ávido por descifrar el enigma urbano. Caminar es un acto poético que ha quedado ejemplificado a través de la figura del flâneur, paseante urbano por excelencia, quien a cada paso toma contacto directo con la ciudad y extrae de ella un relato. A partir de la premisa de que la ciudad es un texto y caminar una forma de lectura y escritura, el presente artículo propone la recuperación de la figura del flâneur moderno para adaptarlo a contextos posteriores, especialmente, aquellos generados por el uso de las tecnologías. En estos contextos, la actualización del flâneur va a permitir abordar un conjunto de prácticas artísticas contemporáneas, donde los creadores asumen su actitud para promover diferentes lecturas de una ciudad palimpsesto. Finalmente, se expone un proyecto personal donde se hace un uso creativo de la tecnología móvil para reivindicar la presencia en las calles como forma de enriquecimiento de la experiencia urbana. De esta manera, cuestiones como

1 Este texto forma parte de la investigación llevada a cabo por la autora en su tesis doctoral: Flâneur, Ciberflâneur, Phoneur: un paseo de resignificación del flâneur por el espacio urbano moderno, el ciberespacio y el espacio híbrido. Acciones artísticas propias entre 2011-2018.

2 Doctora en Bellas Artes por la Universitat Politècnica de València. Docente en el Departamento de Arte de la Universidad Miguel Hernández de Elche. ORCID: 0000-0001-5562-4345. Correo electrónico: elia.torrecilla@gmail.com
\end{abstract}

ESCENA. Revista de las artes, 2020, Vol. 80, Núm. 1, pp. 96-119 ISSN 2215-4906 
la vigilancia y el control que vienen dadas por la tecnología son subvertidas a través del arte, que se sirve del potencial de los medios locativos para proponer una apropiación poética del espacio.

Palabras clave: flâneur; ciudad; arte; paseo; nuevas tecnologías; espacio híbrido

\begin{abstract}
Starting from the premise that the city is a text, and walking a way of reading and writing, this article proposes the recovery of the figure of the modern flâneur to adapt it to later contexts, especially those generated by the use of technologies. In these contexts, the updating of the flâneur will allow us to tackle a set of contemporary artistic practices, where the creators assume their attitude to promote different readings in a palimpsest city. Finally, a personal project is exposed where a creative use of mobile technology is made to claim the presence on the streets as a way of enriching the urban experience. In this way, issues such as surveillance and control that are given by technology will be questioned through art, which uses the potential of locative media to propose a poetic appropriation of space.
\end{abstract}

Keywords: flâneur; city; art; walk; new technologies; hybrid space 


\section{Introducción}

En este artículo se propone la recuperación del flâneur como figura paradigmática de la experiencia urbana moderna, con el fin de verificar su pervivencia en los nuevos espacios generados por el uso de la tecnología. La importancia de adaptar la figura del flâneur moderno a estos nuevos entornos reside en que se convierte en una estrategia analítica que permite explorar y comprender nuevas claves y prácticas artísticas surgidas desde estos contextos. Para llevar a cabo esta actualización, se parte de la metáfora de la ciudad como texto y se observa cómo la flânerie se convierte en una forma de lectura y escritura; un acto a través del cual el artista puede tomar un contacto directo con la ciudad, leer sus signos y las múltiples capas que componen la ciudad-palimpsesto. En el camino trazado por esta investigación, se propone un paseo por el espacio virtual, donde encontramos una actualización del flâneur baudeleriano; un ciberflâneur, que navega a la deriva a través del hipertexto, leyendo y escribiendo el espacio que transita, como una forma de arte de producir lo cotidiano.

Desde la experiencia virtual, visual y vertical del ciberespacio, se propone un aterrizaje en el espacio urbano actual, que se sitúa entre lo físico y lo digital, lo que da lugar a un espacio híbrido. En este entorno, se retoma la metáfora de la ciudad como texto y de la flânerie como una forma de lenguaje; un hecho que se hace más visible a través del empleo de los medios locativos. Se aborda a través de la práctica artística contemporánea, donde encontramos algunos ejemplos en los que el artista asume la actitud de flâneur, pero esta vez es un flâneur hiperconectado que escapa al sistema panóptico haciendo un uso creativo de las herramientas tecnológicas.

La existencia del flâneur en el espacio híbrido, queda demostrada a través de la práctica artística contemporánea, donde el medio tecnológico se convierte en herramienta y oportunidad para promover la interacción entre artistas y usuarios, en un proceso de lectura y escritura de la ciudad-texto en tiempo real. A través de los ejemplos que aquí se visitan, puede observarse cómo las huellas de los desplazamientos físicos y virtuales muestran que el caminar es un acto que permite apropiarse del espacio, al mismo tiempo que se hace un uso subversivo de unos dispositivos tecnológicos basados en la vigilancia, el rastreo y el control. Con estas prácticas, en las que el arte asume la flânerie como actitud y estrategia, se revela, a cada paso, una reivindicación de las prácticas cotidianas que enriquecen la experiencia urbana con poesía y serendipia, logrando transformar el espacio en un lugar.

ESCENA. Revista de las artes, 2020, Vol. 80, Núm. 1 (julio-diciembre), pp.96-119 
La ciudad como un libro abierto: el flâneur como

Artículo

lector y escritor del espacio híbrido...

\section{El flâneur "al pie de la letra"}

No basta con vivir en la ciudad, si no se alcanza desde su mismo rechazo, si no se entra en ella por calles que no son las de los planos. Una ciudad es también un fantasma que solo la ingenuidad del habitante cree domesticable y próximo; apenas unos pocos saben del mecanismo interior que hace caer las fachadas y da acceso por oscuros pasajes a sus últimos reductos.

(Cortázar, 1968, p. 46)

Imaginar la ciudad como un libro abierto es una metáfora que despierta la imaginación y resulta sugerente a la hora de emprender un paseo, con la ilusión de un lector que realiza su ritual personal antes de sumergirse de lleno entre las páginas de un libro. La descripción de la ciudad como un texto que se lee es una imagen recurrente tanto en la literatura como en la arquitectura y el urbanismo, pues tanto el espacio urbano como el texto literario comparten propiedades similares, al ser ambos espacios de producción de sentido y procesos activos, transformadores. Del mismo modo, son muchas y muy diversas las prácticas artísticas que emplean el caminar como metodología, en las cuales el artista se sirve de esta actividad como una manera de tomar conciencia del (con)texto circundante, para comprenderlo y mostrar así una nueva realidad.

Baudelaire llamó al artista a salir a la calle, a ocupar las aceras y observar, bajo las luces de gas, al hombre de la multitud y así convertir la ciudad en un escenario plenamente artístico, pues según el poeta, para que el arte sea actual, el artista debe permanecer en contacto con los signos de su época. Es en la ciudad donde estos se encuentran en estado puro, por ello, la flânerie o la deambulación se convierte en un acto inmejorable mediante el cual el artista puede tener relación con ellos:

La tierra, bajo mis pies, no es más que un inmenso periódico desplegado. A veces pasa una fotografía, es una curiosidad cualquiera y de las flores surge uniformemente el perfume, el buen perfume de la tinta de escribir. (Breton, en Careri, 2002, p. 85).

En el año 1863, en El pintor de la vida moderna (2013), Baudelaire plasma la esencia del flâneur, figura paradigmática de la experiencia urbana del París del siglo XIX, convirtiéndose en el precursor e inventor de un nuevo universo literario, resultado de un concepto diferente de vida que supuso la modernidad, definida por él mismo como "lo transitorio, lo fugitivo, lo contingente" (p. 22). Inspirado en la actitud del flâneur, reflejada en los escritos de Baudelaire, Benjamin hará de esta figura un concepto de interés y objeto de estudio para los académicos de finales del siglo XX, al dejar una inmensa colección de citas y notas para la construcción de un libro no escrito, el Libro de los pasajes (1982). Tal y como explica Cuvar-

ESCENA. Revista de las artes, 2020, Vol. 80, Núm. 1 (julio-diciembre), pp. 96-119 
dic (2002, p. 59) existe una flânerie textual en la obra de Benjamin, porque el conocimiento que adquiere el flâneur se da a través de las desviaciones que lo sumergen en un tiempo extendido, un desvío que el propio autor emplearía como método de conocimiento.

En este sentido, la ciudad puede ser entendida como un texto formado por los fragmentos que lo componen. A través del Libro de los pasajes la ciudad puede ser leída como tal, pues los escritos de Benjamin son una forma de "escribir la ciudad", en la que el conjunto de citas que lo componen se convierten en calles y pasajes. A partir de ellos, el lector puede crear sus propios recorridos, porque "aquello que está escrito es como una ciudad en la que las palabras son miles de pasadizos” (Frisby, 1992, p. 100).

La pasión que el filósofo alemán sentía por la capital francesa, se pone de manifiesto en su libro Calle de dirección única, de 1928, en el que se establece un paralelismo entre las acciones de caminar, escribir y leer (algo que también ocurre en Diario de Moscú). En Calle de dirección única, Benjamin recopila un conjunto de textos cuyos títulos hacen referencia a la señalética urbana. Se trata de un libro compuesto por trayectos que podrían perfectamente ser calles, laberintos o pasajes, los cuales conforman una especie de cartografía urbana que hace posible la comprensión y la teorización de la realidad urbana moderna. Caminar por París, de hecho, suele ser descrito como una lectura de diferentes relatos, porque pasear es una manera de escribir (Walser, 2012).

Esto es algo que puede también observarse a lo largo de las páginas de "Un paseo y un libro" (Machado, 1913), cuyo autor "paseaba, lee que te lee". Ello le llevó a adentrarse en "caminos poco frecuentados y largos" para establecer una analogía entre el paisaje descrito en el propio libro y el que atraviesa físicamente: "el libro y el Madrid que recorro son de una calma absoluta" (Machado, 1913, pp. 101-108). A través de esta especie de "libro dentro del libro", tiene lugar un paseo y una lectura de un escrito que deviene espejo, en el que la mirada del lector se separa de vez en cuando del texto literario para dejarla caer sobre el texto urbano. De ese modo, ambos se fusionan para dar "lugar" a la aparición de una tercera lectura con el libro/paseo como acción cognitiva, pues cuando el lector paseante terminaba un capítulo, hacía una pausa y "reconocía los sitios por donde iba pasando" (Machado, 1913, p. 107) -calles o páginas: las páginas de una ciudad, o las calles de un libro-.

Por un lado, en Physiologie du flâneur (1842), la única monografía que se ocupa de esta figura en el costumbrismo francés y en la que el flâneur surge como tipo social histórico reconocible, Huart emplea la metáfora de la ciudad como libro. Un libro sensitivo que es leído por el flâneur que, con su sentido del gusto, del tacto y la vista, lee todos los "deliciosos carteles, rojo, amarillo, blanco, verde, amapola, ese papel tapiz en todas las paredes de París" (Huart, 1842, p. 76). Por otro lado, en La invención de lo cotidiano (2000), Certeau 
aborda las prácticas de lectura del espacio como artes de producir lo cotidiano. De esta manera, la relación que se da entre producción y consumo sería equivalente a la relación que existe entre la escritura y la lectura: escribir es producir el texto; leer es recibirlo del prójimo sin marcar su sitio, sin rehacerlo, es recorrer un sistema implantado -el del textoparecido al orden construido de una ciudad o de un centro comercial.

Certeau realiza una comparación semiótica entre el acto de caminar y el acto de enunciar, definiendo la flânerie como una forma de lenguaje. Una analogía que fue ya anticipada por la literatura en una cantidad notable de escritos; tal y como sucede en "El hombre de la multitud" de Allan Poe (1840), en el que un personaje persigue a otro por las calles de Londres con el fin de averiguar el destino de su trayecto, pero, para la sorpresa del perseguidor, el perseguido no se dirige a ningún punto en particular, sino que se dirige a todas partes. De este modo, aparece de nuevo la metáfora del paseo como forma de escritura y de lectura, donde el flâneur realiza un acto de apropiación del espacio urbano y una lectura del mismo. Así, la retórica peatonal sería un conjunto de enunciaciones que el paseante utiliza con el fin de transgredir el espacio urbano (tales como los atajos, las desviaciones y las improvisaciones). El paseante es un transformador de signos y, del mismo modo que la retórica, es una desviación de la norma lingüística: "Ios caminos presentan una serie de vueltas y rodeos susceptibles de asimilarse a los 'giros' o 'figuras de estilo', dando lugar a una retórica del andar" (Certeau, 2000, p. 113).

Cuando París se convirtió en un espacio nuevo y prácticamente desconocido para sus habitantes, tras la reforma de Haussmann en la segunda mitad del siglo XIX, estos tuvieron que aprender a leerla de nuevo. Esta legibilidad vino dada por la imagen mental que cada individuo tenía de ella, en función de su experiencia personal del espacio, a lo que se sumó el paso del tiempo, ya que la memoria es selectiva y, muchas veces, distorsiona. Es por esto que la representación mental de la ciudad resulta ser normalmente una imagen en movimiento o una superposición de capas. En esta imagen "imaginaria", la relación que existe entre el habitante y el espacio habitado o entre el observador y lo observado, la correspondencia es doble: es un camino de ida y vuelta. Por una parte, la forma física de la ciudad influye sobre la organización de la imagen mental y, por otra, la experiencia, la memoria, los afectos y la cultura del individuo le asignan a un lugar valores, atributos y significados que van a colaborar en la formación de una imagen subjetiva de ese lugar (Nogueras Canadell, 2007).

Esto nos lleva a la idea de ciudad como palimpsesto, compuesta por capas y superposiciones espaciales y temporales en las que se incorporan distintos lenguajes sobre un mismo lugar. Capas que el flâneur va extrayendo para descifrar el texto que forman, al experimentar unos tiempos pasados que se vuelven fantasmagoría en 
el presente. Este paseante sin rumbo recorre la ciudad en busca de material para su escritura; su conocimiento de las calles es minucioso, pues en ellas se refleja la vida misma. El flâneur es una especie de hombre-espejo que pasea por un París que, además, Benjamin describe como ciudad-espejo: "liso como un espejo, en el asfalto de sus calles las imágenes se reflejan” (Benjamin, 1992, p. 73).

El flâneur, considerado por Benjamin como un "botánico del asfalto" (2005, p. 50), se convierte en un lector de palimpsestos, ya que bajo el suelo y tras los muros del siglo XIX, está leyendo los siglos precedentes en una superposición de huellas depositadas a lo largo del tiempo. Como sostiene Barthes (1997), la ciudad es un discurso y, por tanto, una escritura, un lenguaje. La ciudad les habla a sus habitantes y los habitantes le hablan a la ciudad, de modo que estos se convierten en lectores. Para el autor, esta lectura (de la ciudad) conlleva una interpretación erótica, porque la ciudad, desde el punto de vista social y semántico, es el lugar de encuentro con el otro y, en este encuentro, entra en juego el mecanismo de la seducción.

Tanto para Benjamin como para Hessel, pasear es, por tanto, un arte que requiere una reeducación de los sentidos, una idea que el primero retomó de Baudelaire cuando, en El pintor de la vida moderna (1963), este señala que, para ser receptivo al texto subyacente de la gran ciudad, el paseante debe alcanzar un estado de total disponibilidad, y dejar vacante su atención (Muñoz-Millanes en Hessel, 2015). También Kracauer (2011) fue, en ese mismo sentido, antes que nada, un lector: "alguien que vivió descifrando lo que le rodeaba y leyó su vida y la de su tiempo en las huellas de los edificios y las ciudades, de las novelas de detectives, las películas y los espectáculos de cabaret" (Ferrer, 2016, p. 53). En Paseos por Berlín publicado en 1929, Hessel llegó a afirmar que "flanear" es leer la calle, pues el flâneur es un descifrador de textos visuales y humanos, cuyo recurso más importante es la ciudad. Por ello, Benjamin consideraba a Hessel como la reencarnación berlinesa del flâneur parisino, por conocer a la perfección "las artes de recorrer las calles de París" (Hessel, 2015, pp. 15-16).

Pasear es una suerte de lectura de la calle, durante la cual los rostros de la gente, las vitrinas, los escaparates, las terrazas de los cafés, los tranvías, coches y árboles se convierten en letras, todas ellas igual de legítimas que juntas forman palabras, frases y páginas de un libro en constante renovación. Para pasear de verdad es preciso carecer de un propósito muy determinado (Hessel, 2015, p. 150). 
La ciudad como un libro abierto: el flâneur como

Artículo

lector y escritor del espacio híbrido...

\title{
Paseando páginas: el ciberespacio como texto y navegar como forma de lectura
}

\author{
What the city and the street were to the Flâneur, the \\ Internet and the Superhighway have become to the \\ Cyberflâneur. [Lo que la ciudad y las calles eran al flâ- \\ neur, son ahora el internet y la supercarretera para el \\ ciberflâneur]. (Mozorov, 2012, párr. 1)
}

Un hecho que posibilita establecer una analogía entre el ciberespacio y la ciudad, así como pensar en la existencia del flâneur en este espacio virtual, es el análisis como texto. Esto es posible cuando se analiza el desplazamiento (navegación) que aquí tiene lugar mediante el hipertexto, un sistema que aparece en la década de los noventa con el objetivo de unir el mundo de la teoría literaria con el de la tecnología informática y que permite navegar o desplazarse por el entorno virtual de una forma azarosa. Del mismo modo que la ciudad puede ser leída como un texto, el ciberespacio ofrece esta misma posibilidad, porque al igual que la urbe, también proporciona un marco arquitectónico y de interacciones humanas. Así, el empleo de la metáfora del ciberespacio como texto lo convierte en un espacio legible y, por consiguiente, conocido. Este se encuentra formado por datos, la presencia del usuario en el espacio virtual implica un proceso de lectura y escritura de datos-textos que se mueven de un lugar a otro, lo cual da espacio a un desplazamiento a través del hipertexto.

Al igual que le ocurría los habitantes de París tras la reforma de Haussmann, el usuario que accedía al ciberespacio a finales de la década de los noventa se encontraba con un espacio completamente nuevo por descubrir. Si el flâneur tradicional trataba de re-conocer su ciudad saliendo a la calle y paseándola, el usuario de internet explora el ciberespacio; recorre sus calles a través de los hipertextos, navegando con ayuda de exploradores como Safari o Internet Explorer, nombres que en sí mismos resultan reveladores y estimulantes, pues alientan a la aventura de navegar sin rumbo por el océano digital.

Con la aparición de la web 2.0, caracterizada por la participación de los usuarios que comparten información, todos los discursos y enunciados se encuentran disponibles en la red. Ello hizo de esta ciudad virtual una gran escritura colectiva: un lenguaje en el que confluyen diferentes sentidos, tantos como personas recorriendo y apropiándose de sus (ciber)calles. Tal y como explica Cuvardic (2002), "en un proceso similar al crecimiento de las ciudades decimonónicas, la consolidación de la ciudad virtual (internet), permite la tipificación de figuras urbanas virtuales herederas de aquellas que transitaban por las ciudades de los siglos XIX y XX" (p. 228). De esa manera, en internet podemos encontrar transeúntes virtualmente encarnados en flâneurs, paseantes, vagabundos, turistas, jugadores, activistas o piratas y, por supuesto, también voyeurs o lurkers; sin embargo, la figura del ciberflâneur es de la que más éxito ha gozado. 
Al presentarse como un entorno nuevo, el flâneur, actualizado en ciberflâneur, descifra el ciberespacio y los hipertextos al igual que como lo hacía en la ciudad. En este sentido, Rosello (1994) explica que el hipertexto propone una nueva relación entre cuerpo y espacio, porque la propia navegación que tiene lugar al ir de una página a otra a través de enlaces, se convierte en una forma de apropiación del territorio, de naturaleza exploradora y aventurera. De este modo, los cuerpos virtualizados escriben su propio texto en el espacio reconstruyendo mapas y desvelando nuevos caminos. Así, internet podría ser comprendido como una gran colección de textos que vienen y van. De manera que, desde este punto de vista, el uso de internet puede considerarse como un proceso de lectura y escritura.

En tanto espacio de escritura, el hipertexto es, según Clément (2000), un nuevo lugar en expansión que tiende a la forma laberíntica, lo cual obliga a que en su escritura haya señales o mapas de recorrido; concluye que el hipertexto es una enunciación pionera cuya característica más decisiva es "ir a la deriva" (Rodríguez, 2003). A diferencia del texto clásico que jerarquiza, organiza y clasifica la información, el hipertexto no se interesa por fijar el sentido. Además, su especificidad consiste en una visión ambulante, la cual exige del lector que en cada cruce de camino tome las decisiones que su propio recorrido induce, a la manera de los libros "Elige tu propia aventura": libros de hiperficción explorativa (también conocidos como "librojuegos") en los que el lector decide el rumbo que toman los personajes, modificando, a su elección, la trama de la historia.

Al igual que en la deambulación urbana, la ciberflânerie o "navegación a la deriva" que tiene lugar en el ciberespacio, a través del hipertexto, conlleva un mismo proceso de lectura y mapeado (Lemos, 2001). Por un lado, la lectura que pone en relación el cuerpo y el texto y, por otro, el mapeado implica la relación entre el cuerpo y el espacio. De esta manera, Lemos sostiene que tanto la flânerie urbana como su práctica en el ciberespacio produce una fusión entre la figura del lector (que sigue el mapa) y la del escritor (que hace el mapa).

A la vez herramienta para el escritor y medio para el lector, los documentos en hipertexto permiten a los escritores, o a grupos de autores, conectar datos entre sí, crear trayectos en conjunto de material afín, anotar texto ya existente y crear notas que remitan tanto a datos bibliográficos como al cuerpo del texto en cuestión... El lector puede pasearse por esos textos anotados, referidos y conectados de forma ordenada, aunque no secuencial. (Landow, 1995, p. 17)

Es por ello que, entre la flânerie del poeta, el artista urbano y la ciberflânerie, no hay mucha distancia: vagar por la ciudad y "clickear" en sitios de internet, suponen una manera de escribir leyendo y de imprimir el trazo o huella en el espacio maleable de lo cotidiano. Lejos de una simple consumición pasiva del espacio (físico o virtual), aquí tienen lugar 
La ciudad como un libro abierto: el flâneur como

Artículo

lector y escritor del espacio híbrido...

una serie de procesos de seducción, desvíos y apropiaciones que dotan de sentido a los espacios que son vividos como experiencia.

\section{El espacio híbrido como (hiper)texto y navegar como forma de lectura}

Para realizar una aproximación al espacio híbrido como texto, se debe considerar tanto la analogía que existe entre ciudad y texto, que tratábamos anteriormente, como las relaciones entre cuerpo y espacio que se producen a través del hipertexto. El desplazamiento que el usuario realiza en este espacio es una escritura generada en tiempo real en la que la navegación está guiada por unos dispositivos basados en GPS, los cuales registran el recorrido realizado. Estas herramientas, denominadas medios locativos, generan una capa de información digital en el espacio físico que da lugar al espacio híbrido; una superposición de estratos que nos acerca de nuevo la idea de ciudad como palimpsesto.

Para analizar de qué manera la tecnología móvil cambia nuestra experiencia cotidiana del espacio practicado, es importante volver a Certeau (2000), quien recurre a la figura del flâneur para revisar la experiencia que el transeúnte tiene a nivel de calle. El autor describe la mirada desde las alturas que obtiene el voyeur, que abarca la ciudad en su totalidad con una sola mirada. Frente a esta mirada vertical y distanciada del voyeur, Certeau propone recuperar la forma más antigua y lenta de movilidad personal: caminar a pie como forma de escritura urbana, una experiencia llevada a cabo por caminantes, los practicantes ordinarios de la ciudad, los "wandersmänner, cuyo cuerpo obedece a los trazos gruesos y a los más finos (de la caligrafía) de un texto urbano que escriben sin poder leerlo" (Certau, 2000, p. 105). Sin embargo, es preciso matizar que, aunque en su experiencia horizontal, el flâneur hace uso de todos sus sentidos, tiene un predominio de lo visual, pero:

No vayamos a confundir el flâneur con el mirón, hay un matiz. El simple flâneur... está siempre en posesión de su individualidad. La del mirón, por el contrario, desaparece absorbida por el mundo exterior, que le golpea hasta la embriaguez y el éxtasis. El mirón, ante el flujo del espectáculo que ve, se convierte en un ser impersonal, ya no es un hombre: es público, es muchedumbre. (Benjamin, 2005, p. 433)

Certeau argumenta que el hecho de ver, organizar y experimentar la ciudad es algo que se produce a nivel de calle, a través de caminar, pues los caminantes, con sus rutas entrelazadas, dan forma al espacio. Son escritores del texto de la ciudad, por ello, considera el caminar como un acto discursivo. Pero en lugar de emplear el verbo, los caminantes utilizan el espacio para articular enunciados. Así, "caminar supondría la experimentación de un escenario físico integrado que ofrece una fuerte sensación de seguridad emotiva, estableciendo una relación armoniosa entre el individuo y el mundo exterior" (Lynch, 1998, p. 12).

ESCENA. Revista de las artes, 2020, Vol. 80, Núm. 1 (julio-diciembre), pp. 96-119 
En este punto, es necesario retomar el pasaje de Benjamin que hace referencia tanto al elemento arquitectónico preferido del flâneur, como al conjunto de citas. El pasaje es una forma de experiencia urbana que presenta rupturas, fragmentos y discontinuidades, que construye constelaciones móviles y abiertas: citas, pasajes o calles que pueden ser transitadas a través de su obra. Esto lo enlazaría con el hipertexto, ya que ambos conectan calles y pasadizos; abren paso a otros espacios y proponen nuevas relaciones entre estos y el cuerpo.

"Navegar" es la acción que tiene lugar durante el desplazamiento de una página a otra a través de links y desde el otro lado de la pantalla; una interfaz que ha ido disminuyendo de forma progresiva su tamaño hasta lograr entrar en nuestros bolsillos. Teléfonos convertidos en pantallas móviles inseparables de nuestros cuerpos, que se desplazan por la ciudad física mientras consultamos, creamos y compartimos información. En este sentido, es posible pensar en el espacio híbrido no solo como palimpsesto, sino también como un hipertexto.

La fusión de las figuras del lector y del escritor que tiene lugar en el ciberespacio se pone aquí de manifiesto con el empleo de los medios locativos, que combinan tecnologías de localización como GPS, teléfonos móviles, WI-FI y Bluetooth, entre otros, con servicios de localización como la navegación, el rastreo, la emergencia..., medios que son utilizados desde la práctica artística. Son muchos los artistas que se han servido de estos medios para plantear cuestiones como la vigilancia y el control. No olvidemos que estas tecnologías implican nuevos sistemas de vigilancia electrónica y, por tanto, representan un perfeccionamiento y una mutación histórica del dispositivo panóptico de Bentham (Whitaker, 1999). Proyectos artísticos registran, al mismo tiempo, la caligrafía del desplazamiento y la lectura que se realiza del espacio urbano, muestran cómo la hibridación de las figuras del lector y escritor, que ya tenía lugar en el ciberespacio, se acentúa en el espacio híbrido, debido a que al desplazarse por él se generan una enorme cantidad de datos (rastros), mientras se navega por el espacio urbano.

Un análisis profundo sobre arte y medios locativos lo encontramos en Exploraciones creativas. Prácticas artísticas y culturales de los nuevos medios (San Cornelio \& Alsina, 2010). Los autores explican que, en general, los medios locativos se definen como medios de comunicación ligados a un lugar. En otras palabras, medios digitales ligados a espacios físicos que, en consecuencia, desencadenan interacciones sociales. En este sentido, Manovich (2006) sostiene que estos proyectos artísticos basados en la locatividad aportan la novedad en que se hace uso de la tecnología para expresar y catalogar relaciones espaciales.

A partir de la consideración de la flânerie, tanto en su vertiente física como en la virtual, en el análisis realizado por Cornelio y Alsina (2010) se distinguen dos tipos de uso que hace el arte de los medios locativos. Por un lado, un uso anotativo, donde encontramos acciones sobre el mapa, como el etiquetado virtual de emplazamientos geográficos. Aquí se 
encontraría la producción de mapas personalizados a través de herramientas como Google Maps o Google Earth. Es decir, un geotagging o etiquetado virtual del mundo. Por otro lado, encontramos los usos fenomenológicos, que se refieren a la trazabilidad de recorridos y movimientos del caminante en el espacio, esto es, rastrear la acción del sujeto en el mundo.

Con el empleo de los medios locativos, el cuerpo se desplaza por el espacio horizontal, mientras se realiza su seguimiento desde el vertical; una navegación personal que ha evolucionado desde una mirada hacia arriba (con la observación de las estrellas para orientarse) hasta una mirada hacia abajo, dirigida a la consulta de terminales digitales que capturan las señales de satélite y que pueden ser visualizadas en la palma de la mano. Esto nos llevaría a la práctica del GPS drawing, de la cual el artista Jeremy Wood es pionero, tal y como veremos más adelante, y de la que podemos encontrar una referencia temprana y "analógica" en La ciudad de cristal perteneciente a La Trilogía de Nueva York de Paul Auster (1987): "sin ser consciente de tener una razón concreta para ello, Quinn buscó una página en blanco del cuaderno rojo y bosquejó un pequeño mapa de la zona por la que se movía Stillman" (Auster, 1987, p. 77). Luego, el personaje, repasando cuidadosamente sus notas, empezó a trazar con su bolígrafo los desplazamientos que Stillman había hecho en un solo día; el primer día en que él había llevado un registro completo de los vagabundeos del anciano. El resultado fue el siguiente:

Figura 1. Planos del recorrido llevado a cabo por Quinn en su seguimiento a Stillman.
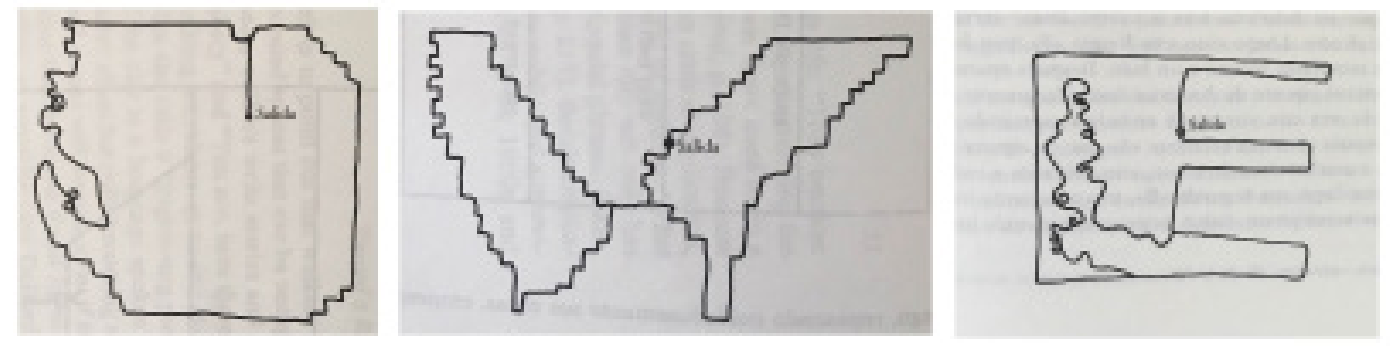

Fuente: (Auster, 1987, pp. 78-79)

La manera en que el perseguidor va registrando los pasos de su perseguido en esta historia de detectives y flâneurs muestra, de una forma bastante clara, la idea del caminar o navegar como forma de escritura y lectura en el espacio híbrido. Allí, la experiencia horizontal se mezcla con la vertical; una mirada distanciada desde la cual es posible distinguir los trazos del trayecto. Lo mismo ocurre con la práctica del GPS drawing, en la que la tecnología GPS va registrando el movimiento del cuerpo en el espacio, mientras realiza un dibujo invisible en el mismo y que solo se muestra gracias al sistema de posicionamiento global. 
Se trata de una acción y un gesto próximos al juego, en el que es posible dibujar mientras se camina. Esto plantea una reflexión acerca del modo en que cada individuo recorre su espacio, así como la revisión de cuestiones relacionadas con la representación cartográfica geopolítica, "oficial" y objetiva, que contrasta con aquella que recoge la experiencia subjetiva de los lugares transitados y la orientación o desorientación del paseante.

A través de la práctica del GPS drawing, el cuerpo se vuelve una suerte de pincel que va dejando su trazo por el lienzo en blanco que es el espacio transitado. En esta obra de Jeremy Wood titulada Meridians (2006) ${ }^{3}$, el artista parte de la cita de Melville en Moby Dick: "It is not down in any map; true places never are [No está marcado en el mapa; los verdaderos lugares nunca lo están]" (Melville, 2003, p. 61). Así, establece dos líneas paralelas que corresponden al Meridiano de Greenwich y al Meridiano GPS.

Figura 2. Meridians, (detalle), "True Places" in Greenwich Park, Londres

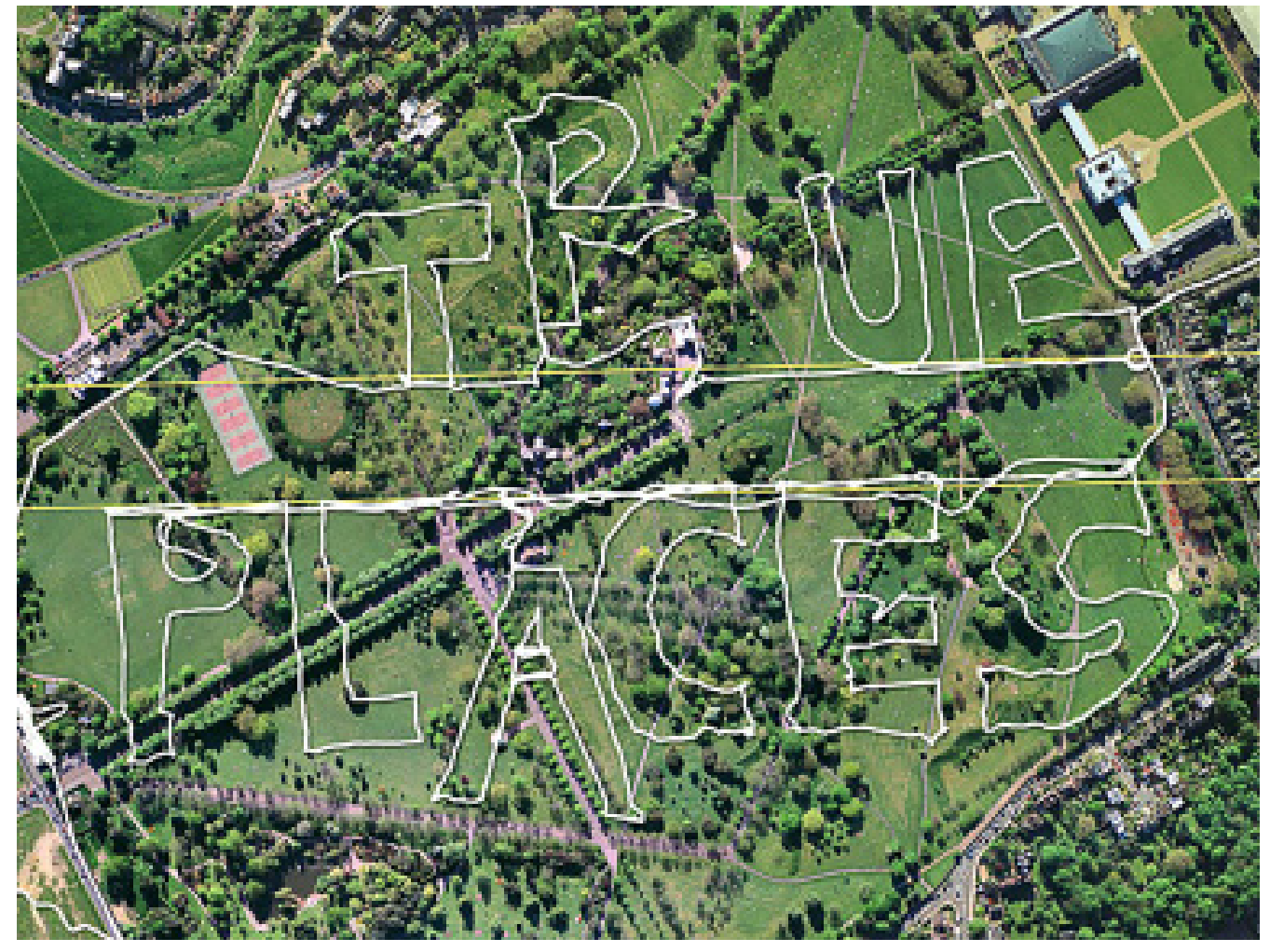

Fuente: Jeremy Wood. Meridians. A voyage along two arbitrary lines, 2006.

${ }^{3}$ Proyecto completo está disponible en: https://www.jeremywood.net/artworks.html 
Otra propuesta que puede ser leída en "clave de flânerie" en el espacio híbrido, es Life: a user's manual, de Michelle Teran, 2003-2006. Una acción en la que la artista, convertida en un personaje nómada, recorre la ciudad con un escáner de frecuencias de vídeo que utiliza para interceptar la videovigilancia, en directo, transmitida tanto desde espacios públicos como privados. Imágenes en tiempo real que se visualizan en la propia calle, a través de una pantalla móvil, un carrito de la compra, un carro de madera, una maleta... hace visibles y audibles las capas ocultas y fragmentos urbanos a los que normalmente no se tiene acceso, y muestra cómo el espacio electromagnético se superpone a los espacios más tangibles y perceptibles de la ciudad transformados en fantasmagoría (Torrecilla, 2018, p. 354).

Pero quizá la idea del espacio urbano híbrido como hipertexto se hace más evidente en Las calles habladas de Clara Boj y Diego Díaz (2016). Se trata de un experimento sonoro de narrativa geolocalizada, que se construye en tiempo real con la información encontrada en internet relacionada con las calles que se van transitando. La aplicación propone un mapa aleatorio en relación con el lugar en el que uno se encuentra y propone una ruta. Al caminar por esa área, se escucha la lectura de la información textual publicada en internet en relación con estos lugares y sus nombres. Esta lectura se crea sin ningún tipo de filtro, por lo que se escuchan historias sobre noticias, información de páginas web, blogs, entre otras fuentes, junto con información sin sentido, símbolos, códigos. Es una pieza que le pregunta a la ciudad, hace hablar a sus calles y en la que los usuarios ejercen de "cursores humanos", por lo que, de alguna manera, a través de este tipo de propuestas, es posible pensar en los medios locativos como "guías" de navegación en el espacio híbrido (Torrecilla, 2018, p. 365).

Por otro lado, encontramos acciones como Constraint City - the pain of everiday life de Gordan Savicic (2008), una performance que explora el espacio urbano a través del cuerpo. Se trata de un corsé sensible a las redes inalámbricas: cuanto más próximas se encuentran, más aprieta. Los recorridos realizados durante las acciones son registrados en una cartografía del "dolor esquizogeográfico". A través de esta tecnología portable en forma de corsé, el artista no solo escribe, sino que, a la vez, realiza una lectura del código de la ciudad. Paseos en los que el performer, convertido en "flâneur híbrido" se convierte en un cuerpo sensible a la ciudad-wifi.

Con estos trabajos se pone de manifiesto cómo, frente al control que se ejerce en las ciudades, el artista, encarnado en flâneur híbrido, recurre a las nuevas herramientas para hacer uso de ellas con unos fines muy concretos: subvertir el excesivo control y vigilancia urbana que convierte a los ciudadanos en consumidores. Al mismo tiempo permite reflexionar sobre el concepto de espacio, sus transformaciones y sus posibles representaciones, donde los medios locativos adquieren especial relevancia. 


\section{Nota al pie: S O Y (aquí)}

Según la convicción de que la práctica artística es generadora de la teoría y viceversa, a continuación, se muestra, a modo de "nota al pie", una propuesta artística personal titulada SOY (aqui) que fue llevada a cabo en las calles de Valencia (España) en 2016 y empleó la flânerie como estrategia. Esta acción comienza con un paseo sin rumbo por la ciudad en busca del acontecimiento urbano. En uno de estos desplazamientos, encuentro a una persona que vende diversos objetos en la calle, entre los cuales, asoman tres letras (una "s", una "o" y una "y"), que debían pertenecer, probablemente, a los rótulos de algún establecimiento. Las compro y comienzo a caminar y, de manera automática, levanto las letras componiendo la palabra "SOY": si caminar es un modo de estar, es mucho más un modo de ser.

Tras esta casual e impulsiva manera de actuar, aparece un pensamiento sobre la idea del "ser" y "estar" a través del paseo, lo que puede ser asociado con el "usted está aquí" tan frecuente en planos y cuyo símbolo Google Maps convirtió en icono. Así, se lleva a cabo una exploración virtual del mismo espacio donde, previamente, había tenido lugar la acción (física) espontánea. Desde esta visión vertical a través del mapa virtual, se observó de una manera clara que, en los alrededores de esa calle, se dibujaba la forma de los tres caracteres adquiridos, por lo que, a través de la herramienta "Google my Maps", se trazó, a modo de esbozo, el recorrido que compone la palabra.

Figura 3. Proyección digital del recorrido SOY (aqui)

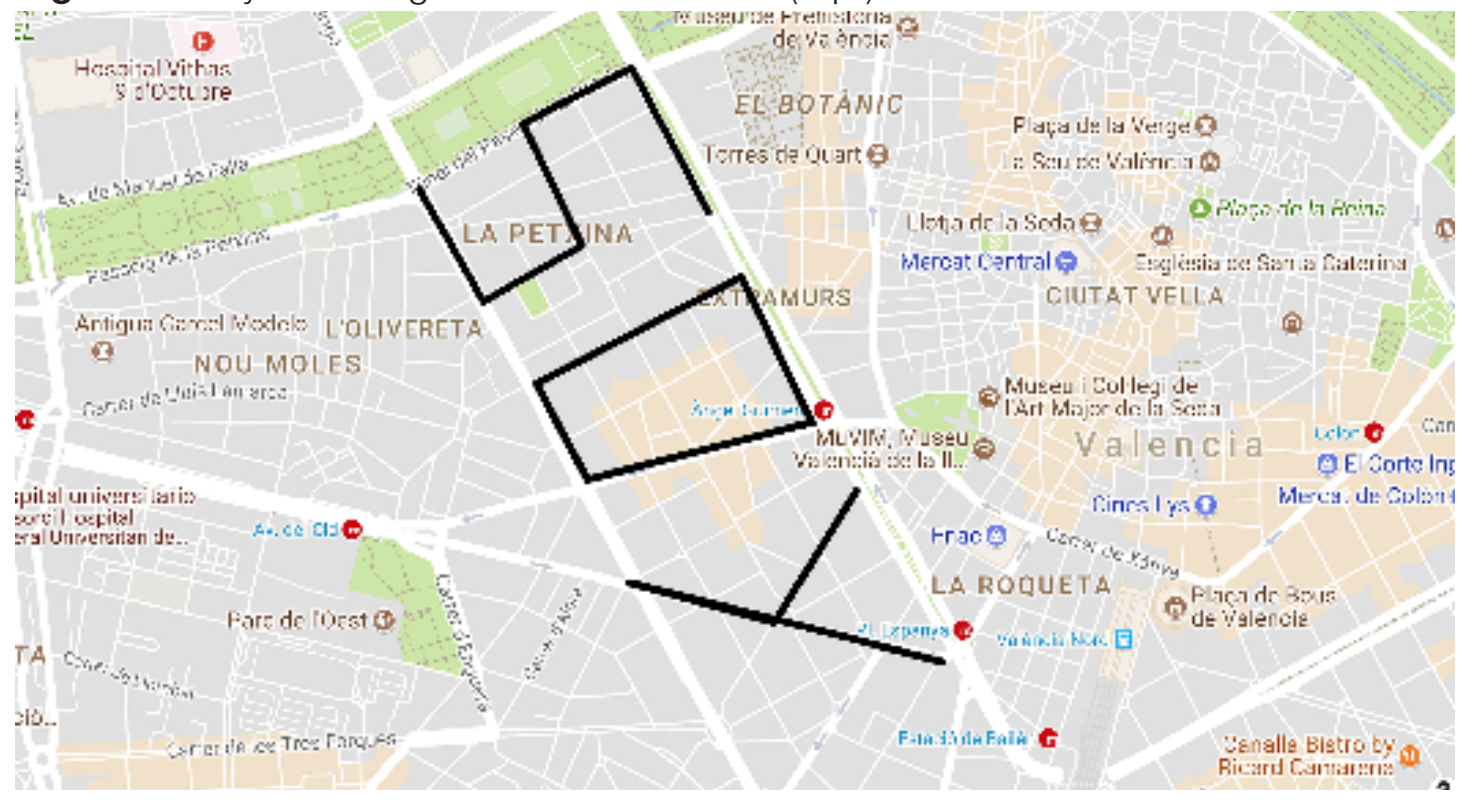

Fuente: Elia Torrecilla (2018, p. 492).

ESCENA. Revista de las artes, 2020, Vol. 80, Núm. 1 (julio-diciembre), pp.96-119 
Se continuó con la proyección del trayecto a seguir y se llevó a cabo un paseo virtual, vertical y visual a través de Google Maps siguiendo el recorrido trazado a través de mis dedos ejerciendo de piernas. Como resultado, se obtuvo el registro de la (ciber)acción a través del vídeo SOY (aqui $)^{4}$.

Figura 4. Capturas de vídeo SOY (aqui)
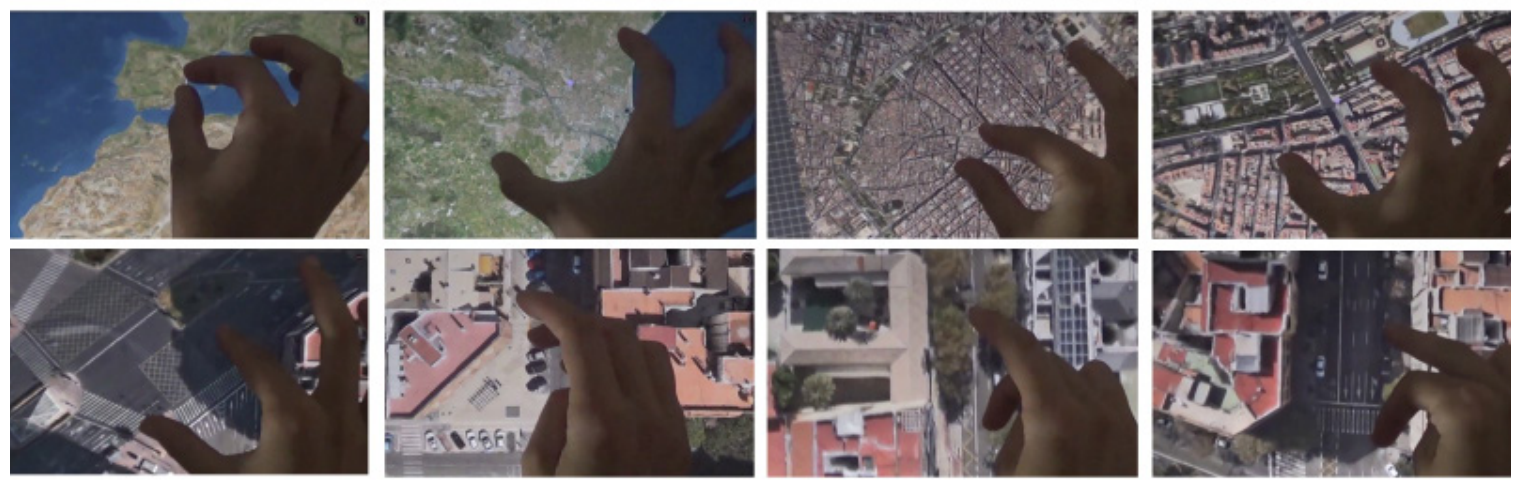

Fuente: Elia Torrecilla

Como hemos visto, la visión vertical que se obtiene desde el ciberespacio, a través de la visualización de los sitios en herramientas como Google Maps, próxima a la mirada del voyeur, contrasta con la experiencia horizontal; es decir, con aquella que obtiene el flâneur en su cuerpo a cuerpo con la ciudad. En el espacio híbrido, con el empleo de los medios locativos, el flâneur se desplaza por el espacio horizontal, mientras sus movimientos son rastreados desde el vertical; un hecho que nos lleva a la práctica del GPS drawing, anteriormente mencionado.

De este modo, una vez planeado el trayecto desde el espacio virtual, se procedió a pisar las calles anteriormente transitadas mediante el deslizamiento de los dedos sobre la pantalla táctil del dispositivo. El recorrido a pie sería registrado a través de la aplicación MotionX-GPS 5 para trazar, de una manera directa, cada letra, paso a paso (la huella). Sujetando y elevando la letra S, se comienza a caminar su forma, a dibujarla caminando para, seguidamente, realizar lo mismo con los otros dos caracteres.

\footnotetext{
4 Vídeo disponible en: https://www.youtube.com/watch?v=GtKLZiu83hM

5 Aplicación disponible en: http://gps.motionx.com
} 
Imagen 5. Documentación del acto y la huella del recorrido mediante GPS
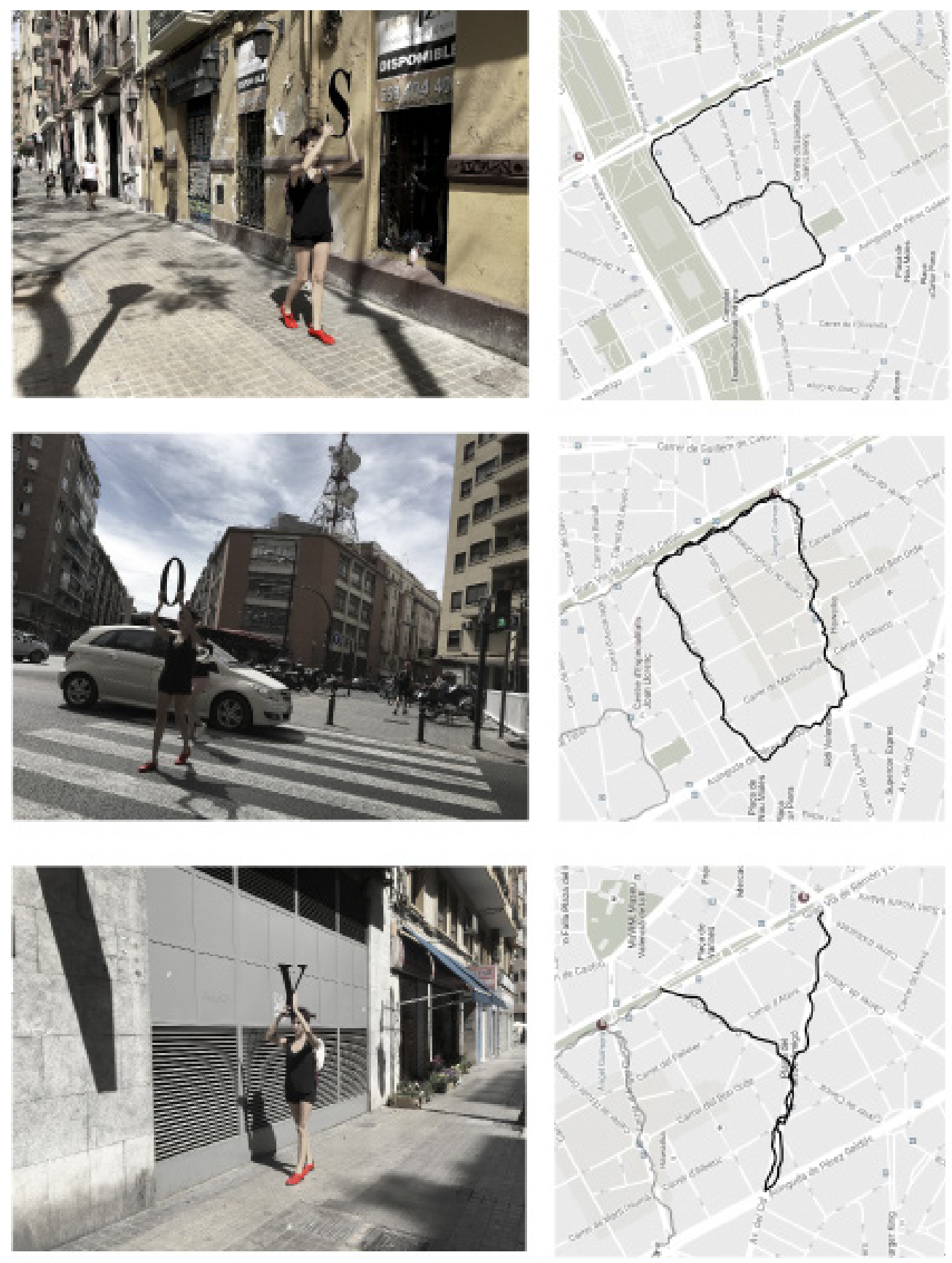

Fuente: Elia Torrecilla 
Como resultado, SOY (aqui $)^{6}$ es un montaje que muestra la documentación de un recorrido lúdico y performático, que comienza con un acontecimiento casual y continúa indagando en la necesidad de habitar el espacio urbano, de explorarlo y recorrerlo. El paseo, convertido en acción artística, permite recuperar el cuerpo. Caminar permite apropiarse del espacio, poseerlo, re-conocerlo y resignificarlo. Es una práctica de libertad. SOY (aqui) es un paseo proyectado desde el espacio virtual y practicado en el espacio físico, un viaje del mapa al territorio que traspasa la pantalla para establecer un diálogo entre cuerpo y ciudad; una caligrafía registrada mediante GPS trazada paso a paso. Una escritura cuyas huellas buscan destacar su presencia en las calles y tomar conciencia de uno mismo en la ciudad, de ser parte del todo urbano: SOY (aquí), es un proceso que está siendo.

En este sentido, recordamos que el flâneur es una especie de topógrafo urbano capaz de descifrar la ciudad, que es su casa, porque la deambula, la callejea y está inmerso en ella. Por lo cual, es posible describir la actividad del flâneur como un work in progress. A través de este trabajo se lleva a cabo la práctica de GPS drawing, en la que el paseo y la cartografía se sirven de herramientas basadas en GPS que van registrando los desplazamientos del cuerpo por las calles, una práctica que muestra un uso lúdico del espacio, ya que hace posible dibujar mientras se camina, y plantea una reflexión acerca del modo en que cada individuo recorre su espacio.

De esta manera, surge la cuestión de que "el movimiento no solo transporta al cuerpo, sino que influye en su representación espacial en el espacio virtual” (Verhoeff, 2012, p. 14). En el GPS drawing el cuerpo se vuelve una especie de pincel o cursor humano que va dejando su rastro por el lienzo o página en blanco que es el espacio transitado. Esto trae de nuevo la idea de caminar como un acto de escritura. Recordamos que Certeau (2000) comparaba el espacio urbano con una página en blanco donde el caminante con su desplazamiento produce un texto.

Para retomar la cuestión del caminar como un modo de ser y estar, y la necesidad que tiene el ser humano de encontrar su lugar en el mundo a través de una identificación con -y a través del- espacio, hace posible pensar que ese "usted está aquí" podría convertirse en un "usted es aquí". Ello podría generar una reflexión sobre la importancia que la autorrepresentación tiene en el espacio híbrido y que se hace visible a través del exceso de selfies y su transformación de la idea de la fotografía, en tanto que se ha pasado de mostrar lo que "ha sido" por un "yo estuve alli". Algo que, en cierto modo, recuerda al conocido

${ }^{6}$ SOY (aqui), fue expuesta en la Sala Universitas de la Universidad Miguel Hernández de Elche en 2016, cuyo resultado puede consultarse en Tejero, D. (comis.). (2016). Puénting, 5 años de saltos a la profesionalización. Elche: Editorial UMH. 
grafiti "Kilroy was here", que muestra la necesidad de, no tanto mostrar el mundo, como de indicar nuestro estar (y ser) en él (Martín Prada, 2012, p. 54).

\section{Fin del trayecto. A modo de conclusión}

A través del registro y la exhibición de las huellas de nuestra existencia, la cual se extiende desde el espacio virtual al entorno físico mediante el uso de los teléfonos móviles, se muestra un rasgo fundamental de las tecnologías ubicuas. Se trata de la aportación de información sobre la manera en que el usuario se relaciona con su contexto. Un hecho que resulta fundamental a la hora de comprender la existencia del flâneur en el espacio híbrido. Esto hace posible que el flâneur baudeleriano se convierta en el phoneur del siglo XX (De Souza e Silva \& Hjorth, 2008), que a su paso va incorporando la experiencia humana y urbana.

En los ejemplos visitados, queda demostrado que desde la práctica artística se destaca la capacidad de interacción y conectividad de las nuevas tecnologías, lo que posibilita la participación de artistas y usuarios en un proceso de lectura y escritura de la ciudad-texto, en tiempo real. Estas huellas activan una capa de información digital en el espacio físico, la cual da lugar al espacio híbrido. A través de los proyectos artísticos aquí mostrados, se observan, de una forma más evidente, las funciones que para Certeau (2000) tiene el caminar: es un acto que permite apropiarse del espacio y su capacidad para convertirla en lugar.

Estas propuestas generan reflexiones sobre el concepto y el uso de espacio; sobre las formas de representarlo y sobre sus transformaciones e interacciones sociales que en él se llevan a cabo. En este sentido, queda demostrada la existencia de un nuevo flâneur hiperconectado, al que, debido al control que la tecnología ejerce sobre el espacio urbano y sobre el usuario, posiblemente se le haya cuestionado ya su derecho a perderse en la ciudad o a descubrir rincones inesperados. Sin embargo, su pervivencia en el espacio híbrido nos ayuda a pensar en nuevas experiencias urbanas que enriquezcan el espacio físico con cierta poesía, que devuelvan una cuota de serendipia al recorrido callejero, y nos ayuden a resignificar los datos o a reencontrarnos en un espacio furtivo (Balestrini, 2012).

A través de la flânerie como método empleado en la práctica artística, es posible realizar una lectura de una serie de trabajos en los que subyace, a su vez, una crítica hacia los dispositivos tecnológicos de vigilancia, rastreo y control. Al mismo tiempo, estos plantean una reivindicación de las prácticas cotidianas, como, por ejemplo, pasear u ocupar el espacio público.

Asimismo, se hace visible la manera en la que, desde la práctica artística contemporánea, se adopta una actitud flâneur para revelar aquellas capas invisibles del palimpsesto urbano. Esto es posible a través del empleo de los medios locativos, lo cual permite observar cómo se convierten en un medio de expresión y catalogación de las relaciones espacia- 
La ciudad como un libro abierto: el flâneur como

Artículo lector y escritor del espacio híbrido...

les. En este sentido, la incorporación de la práctica artística personal ha facilitado entrar en un contacto directo con el espacio a través del cuerpo.

En definitiva, si entendemos la ciudad (la física, la virtual y la híbrida) como un conjunto de signos que forman un texto, podemos comprender el acto de caminar como una forma de lectura y de escritura al mismo tiempo. A cada paso vamos dejando signos que contribuyen a la creación de una ciudad-palimpsesto, cuya experiencia es multisensorial, aunque sigue conservando un predominio de lo visual. Caminar, por tanto, es un proceso de apropiación del espacio por parte del transeúnte que deviene lector y escritor, sin duda, un productor de sentido. Además, la hibridación entre estas dos figuras nos puede llevar a pensar en una fusión entre el Homo typographicus de la Galaxia Gutenberg y el Homo electronicus de la Galaxia Marconi (McLuhan, 1972). Es decir, la unión del predominio de lo visual, lo racional y lo lineal del primero, junto a la experiencia más sensorial, oral y aural del segundo: un acercamiento entre ambos que puede encontrar su encarnación en el propio flâneur en el espacio híbrido.

Frente a las representaciones objetivas del espacio, en las que prevalecen las partes "estables" de la ciudad, tales como los monumentos, los edificios y sus fachadas, el empleo de las nuevas tecnologías en el espacio urbano favorece la creación de unas cartografías y relatos subjetivos, que hacen visibles las partes dinámicas de la ciudad. De esta manera, la experiencia, basada en la movilidad del individuo, agrega nuevas capas de significado en las que surge un espacio vivido, el cual superpone información a las cartografías monopolizadas por el poder y que reivindica, así, la importancia del lugar.

Para finalizar, cabe apuntar que en el epílogo de Paseos por Berlin (Hessel, 1929), Benjamin se refirió al flâneur como "el sacerdote del genius loci", como el guardián del espíritu del lugar que es capaz de captar su esencia y que manifiesta sus cualidades a través del cuerpo que camina, que observa, que siente. El flâneur parece ser el genius loci de él mismo, al celebrar el lugar y sus detalles, y al considerar el acto de caminar como una acción que busca: "Place senses and sense places [localizar sensaciones y sentir localizaciones]" (Feld, Basso \& Keith, 1997, p.10). De esa forma, la flânerie es una invitación a participar en la escritura y en la lectura de nuestras ciudades, a recuperar nuestro cuerpo en un espacio que nos pertenece. Al fin y al cabo, la idea de ciudad es una experiencia subjetiva y llena de conexiones, algo abierto, un (hiper)texto para deambular.

ESCENA. Revista de las artes, 2020, Vol. 80, Núm. 1 (julio-diciembre), pp. 96-119 


\section{Referencias}

Auster, P. (1987). La trilogía de Nueva York. Barcelona: Anagrama.

Balestrini, M. (19 de noviembre de 2012). Inteligencia ciudadana en la metrópolis de los datos. CCCBLAB. Investigación e innovación en cultura. [Página web]. Recuperado de: http://lab.cccb.org/es/inteligencia-ciudadana-en-la-metropolis-de-los-datos/

Barthes, R. (1997). La aventura semiológica. Barcelona: Paidós.

Baudelaire, C. (2013). El pintor de la vida moderna. Madrid: Taurus.

Benjamin, W. (1992). Cuadros de un pensamiento. Buenos Aires: Imago Mundi.

Benjamin, W. (2005). Libro de los Pasajes, Madrid: Akal.

Benjamin, W. (2011). Calle de dirección única. Madrid: Abada.

Careri, F. (2002). Walkscapes, el andar como practica estética. Barcelona: Editorial Gustavo Gili.

Certeau, M. (2000). La invención de lo cotidiano. México: Cultura Libre.

Clément, J. (2000). Del texto al hipertexto: hacia una epistemología del discurso hipertextual. Recuperado de: https://pendientedemigracion.ucm.es/info/especulo/ hipertul/clement.htm

Cortázar, J. (1968). Buenos Aires Buenos Aires. Buenos Aires: Sudamericana.

Cuvardic, D. (2002). El flâneur en las prácticas culturales, el costumbrismo y el modernismo. París: Éditions Publibook.

De Souza e Silva, A. \& Hjorth, L. (2008). Playful Urban Spaces. A Historical Approach to Mobile Games. Simulation and Gaming, 40(5), 602-625. DOI: doi. org/10.1177/1046878109333723

Feld, S. \& Basso, Keith H. (1997). Senses of Place. Mexico: School of American Research Press.

Ferrer, A. (2016). Disiecta Membra. La arquitectura como metáfora. En Rubio Garrido, A. (coord.). Tiempo presente. Permanencia y caducidad en la arquitectura. Valencia: General de ediciones de Arquitectura.

Frisby, D. (1992). Fragmentos de la modernidad. Teorías de la modernidad en la obra de Simmel, Kracauer y Benjamin. Madrid: Visor.

Hessel, F. (1929). Paseos por Berlín. Madrid: Errata naturae. 
La ciudad como un libro abierto: el flâneur como

Artículo

lector y escritor del espacio híbrido...

Huart, L. (1842). Physiologie du flâneur. Paris: Aubert-Lavigne.

Kracauer, S. (2011). Escritos sobre Arquitectura. Barcelona: Mudito \& Co.

Landow, G. (1995). Hipertexto. La convergencia de la teoría crítica contemporánea y la tecnología. Barcelona: Paidós.

Lemos, A. (2001). Ciberflânerie. Cominicaçao na cibercultura. Sao Leopoldo (RS): Unisinos.

Lynch, K. (1998). La imagen de la ciudad. Barcelona: Gustavo Gili.

Machado, M. (1913). Un paseo y un libro. En La guerra literaria (1898-1914), Madrid: Imprenta hispano-alemana.

Manovich, L. (2006). El lenguaje de los nuevos medios de comunicación. Buenos Aires: Paidós.

Martín Prada, J. (2012). Prácticas artísticas e internet en la época de las redes sociales. Madrid: Akal.

McLuhan, M. (1972). La Galaxia Gutenberg. Madrid: Aguilar.

Melville, H. (2003). Moby Dick. Nueva York: Penguin Classics.

Mozorov, E. (4 de febrero 2012). The Death of the Cyberflâneur. New York Times. Recuperado de: https://www.nytimes.com/2012/02/05/opinion/sunday/the-death-of-the-cyberflaneur.html

Nogueras Canadell, C. (2007). La legibilidad de la gran ciudad. Espéculo. Revista de Estudios Literarios, 36. Recuperado de http://webs.ucm.es/info/especulo/numero36/legiciud.html

Rodríguez, J. (2003). Hipertexto, literatura y ciudad. Revista Universitas Humanística, 56, 53-67. Recuperado de: https://revistas.javeriana.edu.co/index.php/univhumanistica/article/view/9696/7929

Rosello, M. (1994). The Screener's Maps: Michel de Certeau's Wandersmäner and Paul Auster's Hypertextual Detective. En Landow, G. (1994). Hyper/Text/Theory. Baltimore: The John Hopkins University Press.

Torrecilla, E. (2018). Flâneur, Ciberflâneur, Phoneur: Un paseo de resignificación del flâneur por el espacio urbano moderno, el ciberespacio y el espacio híbrido. Acciones artísticas propias entre 2011-2018 [Tesis doctoral]. Universitat Politècnica de València. Recuperado de: Disponible en: https://riunet.upv.es/handle/10251/107391

San Cornelio, G. \& Alsina, P. (2010). "Espacios, flujos y lugares: una aproximación estética a los medios locativos". San Cornelio, G. (coord.). Exploraciones creativas.

ESCENA. Revista de las artes, 2020, Vol. 80, Núm. 1 (julio-diciembre), pp. 96-119 
Prácticas artísticas y culturales de los nuevos medios. Barcelona: Uocpress.

Verhoeff, N. (2012). Mobile Screens. The Visual Regime of Navigation. Amsterdam: Amsterdam University Press.

Walser, R. (2012). El Paseo. Madrid: Siruela.

Whitaker, R. (1999). El fin de la privacidad. Cómo la vigilancia total se está convirtiendo en realidad. Barcelona: Paidós. 